\title{
O ribeirurbano e as cidades da Amazônia: a construção de uma antropogeografia
}

The ribeirurbano and the cities of the Amazon region: the construction of an Anthropogeography

Gustavo Rodrigo Milaré Montoia - Doutor em Planejamento Urbano e Regional pela Universidade do Vale do Paraíba (UNIVAP). Professor de ensino fundamental e médio das redes pública e particular de ensino e pesquisador-colaborador do Laboratório de Estudos das Cidades da UNIVAP. E-mail: milaremontoia@hotmail.com.

Sandra Maria Fonseca da Costa - Doutora em Informação Espacial pela Universidade de São Paulo (USP). Professora adjunta da Universidade do Vale do Paraíba (UNIVAP). E-mail: sandra@univap.br.

\section{Resumo}

Esse artigo tem como objetivo propor uma discussão sobre uma antropogeografia das pequenas cidades ribeirinhas da Amazônia. A partir de estudos de caso, intencionase compreender estas realidades como espaços dotados de particularidades próprias do lugar, na identidade denominada como "ribeirurbano", a partir da tríade habitante-lugar-modo de vida. Nessa abordagem, observa-se uma discussão necessária para a construção da cidadania com um novo modelo cívico a considerar nos programas de governo e no planejamento urbano e regional.

\begin{abstract}
This paper aims to propose a discussion about anthropogeography of the small riverine cities of the Amazon region. Using case studies, it is intended to understand these realities as social spaces, provided with particularities, creating an identity denominated as "Ribeirurbano" (urbanriverine), from a triad inhabitantplace-way of life. In this approach, a discussion is necessary for the construction of citizenship with a new civic model to be considered in government programs and urban and regional planning.
\end{abstract}

\section{Palavras-chave}

Amazônia. Cidades Ribeirinhas. Ribeirurbano. Antropogeografia.

\section{Keywords}

Amazon region. Riverine cities. Ribeirurbano. Anthropogeography. 


\section{INTRODUÇÃO}

Pensar nas pequenas cidades da Amazônia é uma tarefa laboriosa. Uma região repleta de pluralidades, dominada pela floresta, mas não apenas verde, é multicolorida, permeada pelo urbano, pelo rural, pela presença marcante do meio natural e pela dinâmica dos cotidianos que marcam esses locais, pertencentes a outro urbano.

É parte de uma região denominada de floresta urbanizada por Becker (1985), pois possui um processo intenso de crescimento econômico e de urbanização. Foi alvo de políticas do governo federal, vista como fronteira agrícola, desde 1970, e como possibilidades de investimentos para o desenvolvimento de projetos agrominerais, a partir do período militar. Atualmente, o discurso de proteção ambiental prevalece na busca por um mercado sustentável (BECKER, 2009, 2013; PRESSLER, 2010).

Assim, nessa região do discurso da exploração de recursos naturais e do desenvolvimento sustentável, que contribui para a sensação de um espaço destituído de pessoas (OLIVEIRA, 2016), estão as pequenas cidades amazônicas. Formadas desde o século XVII, muitas delas foram estabelecidas como protourbes no período da borracha (BECKER, 2013) e, desde lá, vêm sofrendo flutuações populacionais entre períodos de crescimento e crise econômica.

Essas cidades se cristalizaram e se transformaram por dinâmicas urbanas e incorporação de uma realidade tecnológica, que, ao comporem essa realidade, reforça seu caráter intrínseco ao lugar e não necessariamente de estranhamento a ele. Apesar de se inserirem em uma lógica hegemônica global, interagem com a modernidade de acordo com sua característica vernacular.

Dessa maneira, posicionar essas cidades a fim de torná-las emersas no cenário nacional é importante para a definição de políticas públicas, de programas de governo e para se pensar o planejamento urbano e regional que foi definido, muitas vezes, a partir da realidade dos espaços metropolitanos. Muitos autores teceram essa discussão, como, por exemplo, Oliveira (2006, 2016), Trindade Jr. (2011, 2013), Trindade Jr., Silva e Amaral (2008) e Schor (2014), que discutem não apenas um quadro econômico, como também cultural, identitário, simbólico e de redes sociais.

São temas pertinentes para se estabelecer um novo modelo cívico (SANTOS, 2014a), uma sociedade que se reconheça como plural, na construção 
de uma cidadania que não seja desconectada do território. Nesse sentido, este artigo tem como objetivo levantar uma proposição sobre uma antropogeografia das pequenas cidades ribeirinhas da Amazônia, a partir da tríade habitante-lugarmodo de vida, que conceituamos como "ribeirurbano" (MONTOIA, 2018).

Para a construção da proposição apresentada, partiu-se de pesquisas de campo realizadas entre os anos de 2009 a 2018, na realidade das cidades de Afuá e Ponta de Pedras, no estado do Pará, e Mazagão, pertencente ao estado do Amapá. Vários trabalhos já foram produzidos a partir de dados obtidos em pesquisas sobre essas realidades e alguns exemplos são usados neste artigo (COSTA, 2014; COSTA et al. 2015, 2016; COSTA; ROSA, 2017; MONTOIA, 2010, 2018; RANGEL, 2011; CARMO, 2015; VALOTA, 2015; MOREIRA, 2016; LIMA, 2017; OLIVEIRA; COSTA, 2017).

Tais produções, aliadas à pesquisa de campo, geraram novas indagações sobre essas cidades para além das análises econômicas, instigando-nos a uma busca por construir uma antropogeografia que entende as relações do indivíduo com o lugar como fator delineador de uma identidade. Isso porque existe uma dimensão de análise da sociedade local concreta que merece relevo diante daquelas baseadas nas escalas nacionais e internacionais que tornam as realidades locais muito abstratas (SOUZA, 2013, p. 289).

Também foram realizadas leituras de vários artigos e livros de autores que estudaram pequenas cidades da Amazônia, possibilitando-nos, assim, o reforço de nossa proposição e a comparação com outros estudos publicados na construção do conceito de ribeirurbano, que é um elemento de singularidade na região e que merece ser considerado na realização de políticas públicas (MONTOIA, 2018).

Este artigo é parte de estudos realizados pelo Laboratório de Estudos das Cidades da Universidade do Vale do Paraíba, e, embora não seja possível publicar aqui outras variáveis, ele é também resultado de coleta de dados por meio de aplicação de formulários ${ }^{1}$ nos domicílios urbanos nas cidades de Afuá, Ponta de Pedras e Mazagão; realização de entrevistas com agentes municipais e estaduais dos governos dos estados do Amapá e do Pará, da Associação dos Municípios do Arquipélago do Marajó e de agentes públicos e moradores das cidades citadas.

\footnotetext{
Aprovado pelo Comitê de Ética em Pesquisa (CEP), da Universidade do Vale do Paraíba, sob o número 69815317.8.0000.5503.
} 


\section{A CONSTRUÇÃO DE UMA ANTROPOGEOGRAFIA DAS CIDADES RIBEIRINHAS DA AMAZÔNIA}

O termo "Antropogeografia” remete à obra de Ratzel (1982), um geógrafo cujos pensamentos ficaram conhecidos como determinismo geográfico. A partir de uma visão positivista e naturalista, esse geógrafo apontou que o meio físico determinaria o desenvolvimento dos Estados. "O Estado é obrigado a viver do solo" (RATZEL, 1982, p. 100), afirmou o autor, que complementou: "vemos, com efeito, no solo a fonte de toda servidão" (RATZEL, 1982, p. 100). Assim, o desenvolvimento de uma sociedade estava limitado às condições naturais de seu território, estabelecendo-se a necessidade de um “espaço vital” (RATZEL, 1982).

Moraes (2005) afirma que Ratzel, influenciado pela Biologia, transformou a Geografia em uma ciência natural, para a qual a formação da sociedade e sua constituição social dependeria dos recursos que seu espaço viesse a dispor. Pode até mesmo influenciar na formação do caráter dos indivíduos que a compõem.

A principal obra de Ratzel foi o livro "Antropogeografia - fundamentos da aplicação da Geografia à História”, publicado em 1882, no qual definiu o objeto da ciência geográfica como o estudo da influência que as condições naturais exerceriam sobre a humanidade (RATZEL, 1982). A Antropogeografia refere-se a uma forma de análise sistemática, adotada no final do século XIX, relacionada à distribuição das sociedades, à relação entre migração e o meio físico e à influência do meio sobre as pessoas, como mencionado anteriormente. $\mathrm{O}$ homem precisaria utilizar os recursos da natureza para conquistar sua liberdade, pois à medida que a sociedade se expandisse, necessitaria de mais recursos, e se estes fossem escassos, a sociedade não se desenvolveria; daí a proposição do termo "espaço vital".

Santos (2002, p. 31) comenta que essa Geografia escondeu o papel do Estado bem como o das classes, na organização da sociedade e do espaço. Foi uma justificativa para a obra colonial que ocorrera na época. Entretanto, o objetivo desse artigo não é estabelecer relações deterministas com o meio, mas conferir uma ressignificação do termo antropogeografia: o indivíduo, produtor do lugar, e o lugar como reflexo externo e interno, e que pode ser condicionante.

Nessa linha de raciocínio, sugere-se construir uma antropogeografia das pequenas cidades da Amazônia. Integrantes de grandes áreas municipais, são pequenas cidades, e, ao mesmo tempo, espaços de vivência; situações de 
interações que existem de acordo com o lugar, com as atividades, os horários, as pessoas e suas combinações e compartilhamentos, o movimento entre o rural e o urbano e a hibridização desses ambientes no mesmo lugar, no cotidiano, nas redes sociais e nos laços de proximidade. Configuram a produção social do espaço no plano vivido.

Por fim, a construção da formação socioespacial urbana da Amazônia remete a pluralidades que exigem uma compreensão histórica desafiadora. Apesar dessa região ser conhecida como Amazônia Legal, composta pelos estados do Acre (AC), Amapá (AP), Amazonas (AM), Maranhão (MA), Mato Grosso (MT), Pará (PA), Rondônia (RO), Roraima (RR) e Tocantins (TO), este artigo pretende penetrar na realidade das pequenas cidades ribeirinhas particularmente localizadas na margem do rio Amazonas e, em seu delta (estados do Pará e Amapá), onde a produção do espaço vivido e as atuações de políticas públicas tornam-se invisíveis no debate político e acadêmico brasileiro, como se as pessoas ali não existissem.

\section{O PULSAR DAS ÁGUAS E OS ECOS NA FLORESTA: AS PEQUENAS CIDADES RIBEIRINHAS DA AMAZÔNIA}

As origens das cidades da região amazônica remontam ao século XVII, com o surgimento de, principalmente, freguesias e vilas e, em meados do século XIX, muitas outras cidades se constituíram. Diante de vários acontecimentos, discutidos por vários autores - entre eles Becker (1985), Corrêa (1987), Godfrey e Browder (1996), Vicentini (1994), Machado (1999) e Sathler (2009) -, formouse uma malha urbana, com a continuidade das mesmas funções pelas quais haviam sido criadas: local de representação do poder público, com o intuito de arrecadação de impostos; de circulação de produtos para exportação, como os extrativistas, e para importação, como os alimentos; e sede das missões religiosas (OLIVEIRA, 2016, p. 196).

No início do século XX, principalmente após o declínio da economia da borracha, houve crise nas finanças públicas dessas cidades, sem, contudo, significar crise generalizada para "a população da floresta e para os migrantes nordestinos pobres". Especialmente, no estado do Amazonas, a crise significou "a melhoria das condições de vida que já eram precárias" (OLIVEIRA, 2016, p. 197).

Em outros casos, percebeu-se a diminuição da população urbana em períodos de estagnação econômica (MONTOIA, 2010, p. 66). Na cidade de 
Ponta de Pedras/PA, a flutuação da população urbana demonstra momentos de relativa prosperidade ou declínio econômico que se abateu sobre a região, como o marcante período da borracha. Em 1940, a população urbana de Ponta de Pedras teve um acréscimo de 72\%, acompanhado de uma queda e, depois de 1970, com a intensificação da economia do açaí, experimentou novamente esse crescimento populacional.

No terceiro quartel do século $\mathrm{XX}$, o governo federal estabeleceu políticas indutoras de crescimento econômico na região, com a criação de superintendências, de infraestruturas, transporte de cabotagem, construção da rodovia Belém-Brasília, e pós-1960, a política nacionalista militar, inclusive de proteção de fronteiras, na integração entre as regiões Nordeste e Norte e a construção da rodovia Transamazônica (BECKER, 2009; CARVALHO; CARVALHO, 2012).

As cidades amazônicas, localizadas na fronteira da região, à beira de estradas e rodovias, foram influenciadas por projetos econômicos com forte participação do Estado. Ao mesmo tempo, as cidades das calhas dos rios, continuavam, em grande parte, com o padrão urbano tradicional, ribeirinhas, cidades-rio em sua gênese. Surgidas nas margens dos grandes rios e seus afluentes, com ritmos condicionados pela rede hidrográfica e pela floresta, essas cidades ainda possuem a presença marcante do meio natural, com circulação de pessoas e materiais submetidas ao movimento das águas (OLIVEIRA, 2006; TRINDADE JR.; SILVA; AMARAL, 2008).

A água e a floresta são, assim, elementos marcantes e não ignorados na compreensão dessas cidades. Todavia, existe uma dimensão espacial além do encantamento da realidade física (OLIVEIRA; SCHOR, 2008, p. 19). Esta composição de uma natureza que parece se impor diante da produção humana do espaço, contribuiu para estabelecer "redes urbanas múltiplas, legais e ilegais numa geografia exclusiva e peculiar” (OLIVEIRA, 2016, p. 195).

Cruz (2008) corrobora com esta compreensão ao apontar que existe um padrão que é espaço-temporal, estabelecido em um ritmo lento no modo de vida orquestrado pelo sistema rio-várzea-floresta, na coexistência com um padrão estabelecido, pós-1960, estrada-terra-firme-subsolo, que criou uma nova temporalidade mais ágil nesse mercado global que desconhece o lugar, o cotidiano e o direito à alteridade.

Moreira (1960, p. 83), em sua análise regional, chegou a afirmar que o rio é “o condensador demográfico por excelência na Amazônia”, pois "os acidentes 
ligados à hidrografia que formam a base das nucleações humanas na região" são marcados pela tradição e pela dinâmica da natureza, o ritmo das marés, e influenciam o cotidiano social, a materialidade, os trabalhos, a espera, os fluxos, os encontros, o comportamento.

O rio tem três dimensões importantes nestas cidades (CRUZ, 2008, p. 59). É um espaço físico-natural, como o meio de transporte, a fonte de recursos, e o "responsável" pelo ritmo. É um espaço social, pois é o mediador das "tramas sociais"; e um espaço simbólico, pois é a matriz do pensamento imaginário, do sistema de crendices, histórias, lendas, mitos, da cosmologia que insiste em permanecer como fator de resistência.

Wagley (1957) apresentou características bem peculiares dessa sociedade. Gurupá, apresentada pelo autor, é uma cidade fundada em 1639, a sudoeste da ilha de Marajó. Como uma cidade pequena, ribeirinha, apresentou seu cotidiano bem regional. Dentre os resultados de seus estudos, que deram origem à obra "Uma comunidade amazônica" (WAGLEY, 1957), o autor procurou compreender diversos aspectos dessa realidade, ainda presentes, desde a construção material do espaço aos hábitos e atividades presentes: uma cidade com traçado urbanístico "xadrez", de casas disseminadas, e de transporte fluvial.

Apesar de todas as dificuldades e carências, pontuadas por Wagley (1957, p. 22), o mesmo se questionou a respeito dos pensamentos de sua época sobre regiões subdesenvolvidas, quando o determinismo climático era uma explicação aparentemente plausível para as regiões como a Amazônia. O ambiente físico não é um obstáculo ao seu desenvolvimento, pois, como afirmou o autor, “todos os povos têm a mesma potencialidade para melhorar sua condição social" (WAGLEY, 1957, p. 37).

Explicações reducionistas da realidade das cidades ribeirinhas, apesar de serem usualmente de elaboração simples, não completam este quadro de proximidade e distância, de explicação da realidade local com interligações além do espaço presente. Sua antropogeografia requer um grande desafio de compreensão que, conforme Gomes (2017), necessita de um raciocínio mais elaborado.

\section{A NARRATIVA DO RIBEIRURBANO: O QUE AS CIDADES RIBEIRINHAS NOS PERMITEM VER}

A compreensão da antropogeografia das cidades ribeirinhas é um desafio, pois, apesar da presença do Estado, existe uma produção espacial da 
vida diária, segundo a qual as pessoas constroem sua própria existência, pois “o lugar é a base da reprodução da vida e pode ser analisado pela tríade habitante identidade - lugar" (CARLOS, 2007, p. 17). É uma contrarrealidade ao processo de globalização homogêneo, banalizador, fragmentário, que não nega a existência do exógeno, mas apresenta fatores de resistência em sua situação e posição ao que está em seu entorno, que é endógeno, imediato à vista, ou, até mesmo, ignorado pelas forças contemporâneas globalizantes.

Mesmo que a produção do espaço se conecte com relações globais, ela produz o pertencimento, e, assim, a identidade por aquilo que lhe é significativo, próprio de sua história. Nessas cidades, a partir do espectro da paisagem construída, é possível elaborar as relações sociais que lhe deram origem e que podem, no olhar mais profundo, comportar a observação das peças que realizaram sua composição e as mãos que lhe deram vida.

Trindade Jr. (2011, p. 3) afirma que existe uma relação muito próxima entre os objetos espaciais que compõem a paisagem das cidades ribeirinhas da Amazônia e o seu histórico de ocupação. Oliveira (2006) aponta que sua aparência, muitas vezes de aspecto caótico, é o que permanece diante do encantamento que elas tendem a gerar à primeira vista. Entretanto, esse aspecto de equipamentos urbanos inadequados ou de carências pode, simplesmente, levar essas cidades apenas ao diagnóstico de crise, quando o caminho é percebê-las como um lugar de virtualidades e de possibilidades (OLIVEIRA, 2006).

Tais cidades são "herdeiras de espacialidades pretéritas que mostram processos contínuos e descontínuos no tempo e no espaço" (OLIVEIRA, 2016, p. 200), resultados de processos que resultam uma dura vida, que é um sinal de resistência, "não é necessariamente melhor ou pior, mas é outra vida" (OLIVEIRA, 2016, p. 200). Entende-se, assim, a narrativa do ribeirurbano: não é apenas uma mera descrição de um fato, como se justificasse por si mesmo, in loco, mas a construção de um quadro geográfico de análise de variáveis (GOMES, 2017).

Tiemman-Arsenic (2010) realizou uma pesquisa de campo de caráter antropogeográfico sobre as comunidades ribeirinhas no Vale do Rio Negro e em Presidente Figueiredo, estado do Amazonas. Estas localidades possuem algumas características em comum: o uso dos recursos locais para a sua sobrevivência em conflito com as exigências ambientais normativas, a ausência de um sistema de saneamento básico e a perspectiva temerosa para o futuro, pois a maioria dos entrevistados em ambos locais acreditavam que os filhos iriam deixar o lugar em busca de melhores condições de vida. 
Existe uma relação emocional com o espaço de vivência, mesmo com variação entre os diferentes lugares. Quando o local é recurso e não identidade, as pessoas projetam um futuro em outro lugar (TIEMMAN-ARSENIC, 2010). Contudo, para o ribeirurbano, o local é o projeto de construção de sua vida, em primeiro lugar.

Carvalho (2014) apresenta o município de Fonte Boa (AM), que tem uma população dependente de atividades primárias, principalmente o pescado, do pirarucu. As políticas ambientais têm modificado as relações sociais, ambientais e econômicas no município, bem como, causam impacto na rede urbana. Segundo a autora, "a modernização chega a essa cidade pelas políticas ambientais" (CARVALHO, 2014, p. 109).

Em Fonte Boa não há geração de receita própria e o município continua dependente de repasses do governo federal, mas a função de sua sede na rede urbana local se consolida por estas atividades não urbanas. É nesse espaço que a atividade do manejo se materializa, onde ocorre a comercialização, o planejamento, as reuniões das associações de pescadores.

Em Lábrea, estado do Amazonas, Santos et al. (2014) apresentam uma população que mantém na cidade a prática advinda de uma cultura da zona rural ainda permanente: as hortas urbanas. É “um saber local” (SANTOS et al., 2014, p. 139) que passa de pai para filho na manutenção dessa prática na cidade.

A rede de solidariedade, exemplificada nos dois casos acima, denotam uma peculiaridade do ribeirurbano, no qual o rural e o urbano ribeirinhos estão presentes nos fluxos e se "confundem" no próprio espaço urbano, em seus aspetos paisagísticos. O relacionamento em redes sociais chega a ocorrer independente de uma intervenção ou intermediação por meio de políticas públicas. São as redes autônomas de solidariedade e sobrevivência (Figura 1).

As relações políticas apontam outras questões, como as situações que mesclam apatia, oportunismo e manutenção da realidade local de herança coronelista. De acordo com Montoia (2010), a área urbana de Ponta de Pedras é relativamente aglomerada, com moradias no sentido longitudinal aos rios e igarapés, estendendo-se para a terra firme, com casas que mesclam entre construções de alvenaria e madeira, comércios locais dos mais variados, com a representação do poder público local em seus prédios e a vida simples que segue o movimento de chegada de pessoas e produtos diante das marés.

Desvios entre a realidade local e a ação do poder público em suas diferentes esferas foram encontrados, como a suposta participação popular na elaboração 
do Plano Diretor Municipal para cumprimento formal da lei, segundo a qual, até o ano de 2006, municípios com interesse turístico também deveriam ter seu plano elaborado, como era o caso de Ponta de Pedras (MONTOIA, 2010).

Figura 1 - Várzea do Amazonas: cidades-rio

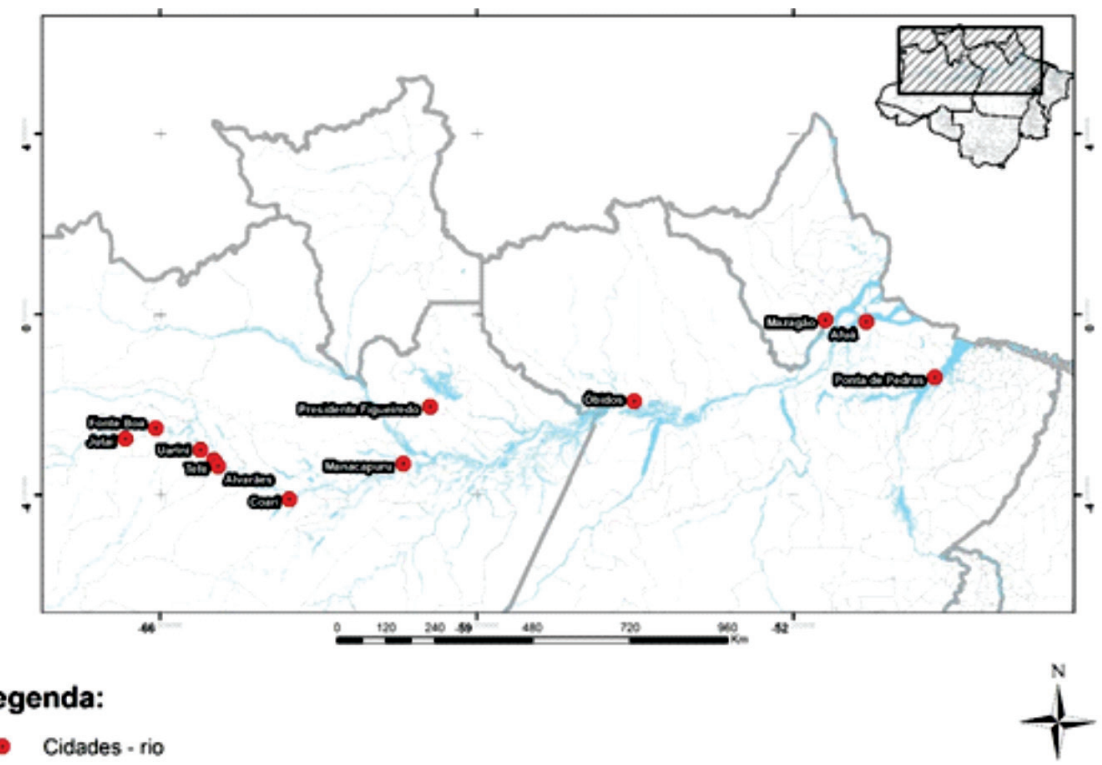

Fonte: Elaborado pelos autores, a partir de dados disponibilizados pelo IBGE (2018).

Estudo apresentado por Rangel (2011), sobre o programa habitacional do governo federal "Minha Casa, Minha Vida", demonstra que o processo de inscrição, seleção dos contemplados para distribuição das casas ocorreu de maneira nebulosa, em um processo turvo, no qual pessoas conectadas a agentes do poder público local foram beneficiadas, sem, contudo, satisfazer às condições de seleção do Programa.

Evidências de ações perniciosas do poder político são encontradas em outras localidades do Brasil. Nessas cidades, entretanto, são o resultado de uma prática diária, na qual a vida local pode ou não se beneficiar, pois o ribeirurbano tem uma relação com a vida política local que é uma mistura entre apatia, oportunismo, desconfiança, rejeição e uma tênue reciprocidade. São relações iníquas.

Costa et al. (2015) levantaram que as terras urbanas de Ponta de Pedras foram cedidas por meio de aforamento e, predominantemente, foram destinadas às famílias consideradas tradicionais na localidade, uma contínua reprodução política em que a relação perniciosa entre público e privado ainda permanece. Estas famílias 
exercem forte influência política sobre o “cidadão comum”, como os comerciantes, empregadas domésticas, servidores públicos, trabalhadores informais.

Na cidade de Ponta de Pedras o rio também é um elemento preponderante que produz resultados sociais: a vida humana que circula, os produtos que vêm e vão entre as cidades e que somam tempo e preço pela distância; os pensamentos de melhoria de vida, de planejamentos sobre formação escolar, propostas políticas, que estão, de certa forma, "sobre o rio".

O rio aqui é natureza segunda, elemento do espaço geográfico, como instância da sociedade, que, em seu movimento dialético, entre a forma e conteúdo, faz parte do todo social (SANTOS, 2002, 2014b). Esses aspectos são relevantes, pois o ribeirurbano os considera todos os dias para realizar viagens, consultas médicas, busca de trabalho, produção de redes sociais, que ele vai em busca e, novamente, volta para casa. O açaí, importante na economia municipal, completa esta relação existencial com as forças produtivas externas, que tem o rio como via principal (RANGEL, 2011, p. 84).

Apesar de carências, dificuldades e desafios diários impostos a essa população, Lima (2017, p. 178) apontou a valorização das relações locais, que são aspectos do ribeirurbano, itens importantes que a população valoriza como qualidade de vida. Valota (2015), em estudo sobre o bairro Carnapijó, área de várzea na cidade de Ponta de Pedras, evidenciou que

segundo os moradores do Bairro Carnapijó, a variação das marés ao longo do dia não interfere no seu cotidiano. Contudo, nos períodos de cheia (inverno), quando ocorre o aumento do nível das águas, os moradores afirmam que se trabalha menos e, como consequência, há redução no valor da renda da família. No verão, período em que as chuvas são menores, o morador trabalha mais e tem a possibilidade de aumentar sua renda mensal (VALOTA, 2015, p. 94-95).

Morar em ambiente de várzea (Figura 2) é uma predominância na formação urbana da Amazônia, composta por pessoas advindas de comunidades ribeirinhas, chamadas de "interior", e que migram destas localidades para as áreas urbanas. São ambientes vulneráveis à ocupação humana, mas é a oportunidade que a população encontra para estabelecer sua residência, na busca por melhores condições de vida (VALOTA, 2015, p. 131). 
Figura 2 - Paisagens ribeirurbanas
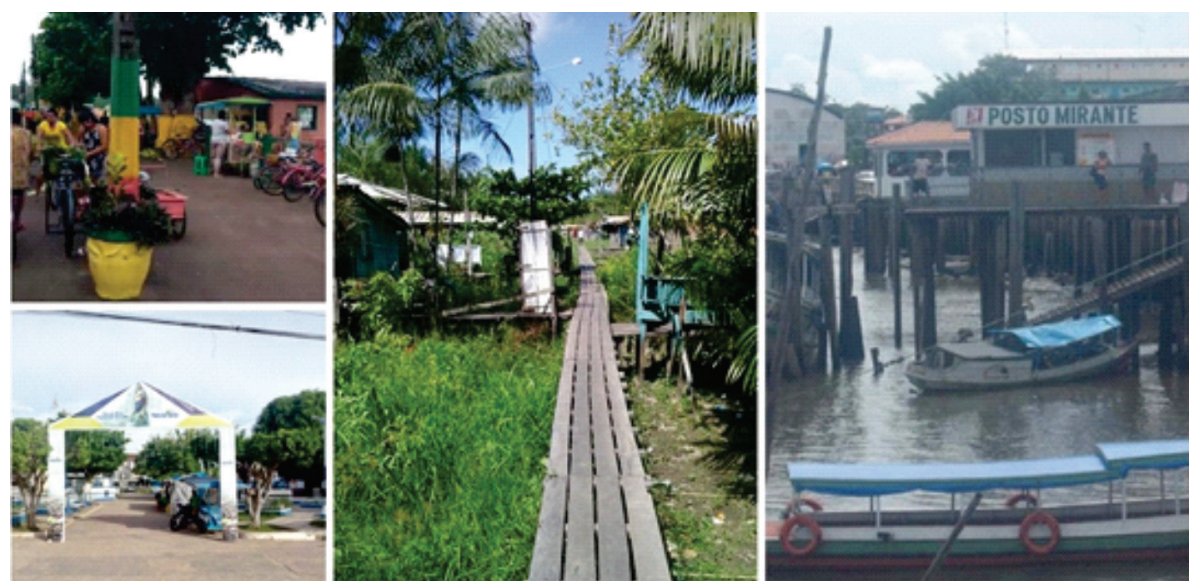

Da esquerda para a direita: orla principal de Afuá/PA; entrada da praça em Ponta de Pedras/PA; bairro em área de várzea em Ponta de Pedras/PA; trapiche em Barcarena/PA. Fonte: os autores, 2015.

Costa et al. (2016) afirmam que mais de um terço dos moradores de Ponta de Pedras habitam a área de várzea, uma paisagem que se confunde com o ambiente rural, geralmente desconsiderada pelas políticas públicas que são ineficazes em dialogar com a população sobre suas reais necessidades: "A população, por seu turno, fica à mercê de si própria na busca de oportunidades de sobrevivência, adotando padrões e modos de vida restritos ao status quo urbano" (COSTA et al., p. 126).

Questão ambiental, geração de empregos, transporte de mercadorias e pessoas, acesso à saúde adequada, infraestrutura urbana que atenda à demanda populacional, transparência na gestão dos recursos públicos e das ações em conjunto com os moradores são parte dos desafios que estas cidades apresentam, bem como sua regularização fundiária. Para Costa et al. (2014), o Estado não pode ignorar esta realidade, inclusive, deve seriamente levar em consideração que este urbano é peculiar e que não pode ser ignorado "pelos tomadores de decisão". E uma discussão

[...] que precisa avançar, em relação à regularização fundiária nas cidades da Região Amazônia, refere-se a essa noção de urbano e à percepção da população e do poder público locais sobre as formas de apropriação desse espaço, discussão importante para subsidiar a elaboração de políticas regionais que viabilizem o desenvolvimento regional com qualidade de vida (COSTA et al., 2014, p. 138). 
São cidades que atraem as populações em busca de melhoria de qualidade de vida em suas mais diversas formas de acesso, inclusive em sua identidade permanente com "fortes vínculos com o ambiente rural, ribeirinho, do seu entorno, em termos de relações sociais e atividades econômicas" (COSTA; ROSA, 2017, p. 94).

Em Barcarena/PA, o urbano é outro exemplo singular. Segundo Carmo (2015), o município apresenta duas realidades urbanas distintas: a chamada velha Barcarena, ribeirinha, reconhecida como área urbana, sede administrativa deste município; e a Vila dos Cabanos, um núcleo urbano com uma infraestrutura adequada à modernização de uma indústria extrativa de recursos naturais, com proximidade a Belém.

Com arruamentos padronizados e largos, presença de hipermercados, sistema particular de saúde, escolas particulares de ensino fundamental e médio, a Vila dos Cabanos, planejada para receber trabalhadores da empresa Albras/ Alunorte, apresenta uma realidade distinta e que torna Barcarena um município com a presença de duas cidades diferentes (CARMO, 2015), a cidade da floresta e a cidade na floresta (TRINDADE JR., 2013).

Estas pequenas cidades possuem em torno de $40 \%$ a $50 \%$ de população urbana, em relação ao total municipal. Contudo, os autores apresentados confirmam que relações econômicas e sociais, seja do manejo para pesca, da produção de alimentos locais e de projetos públicos, são pensadas por um Estado urbano e decidido nesta esfera espacial, o que implica a necessidade em reconhecer este outro urbano longe da lógica do Centro-Sul do país.

Assim, é este ribeirurbano que procuramos compreender por meio da tríade lugar, habitante ${ }^{2}$ e modo de vida. As cidades ribeirinhas têm seu aspecto paisagístico significativo. As casas estão instaladas no sentido do rio, com intenção de chegada e saída, de obtenção de recursos, pois as águas são "uterinas" em sua topofilia. É um modo urbano/rio/floresta, em uma produção dialética entre sociedade e natureza, ambos elementos de produção espacial como um conjunto indissociável entre sistema de objetos e sistema de ações (SANTOS, 2014c).

As moradias em área de várzea, que representam uma característica da região, expressam a produção do espaço pelo habitante local. Transformam-se

2 Stuart Hall (2005) afirma que aquele sujeito previamente vivido como tendo uma identidade unificada e estável está cada vez mais fragmentado, possuidor de várias identidades, algumas vezes contraditórias e não resolvidas. É uma identidade móvel, na qual o "sujeito assume identidades diferentes em diferentes momentos" (HALL, 2005, p. 13), e isso nos leva a compreender que a globalização acaba por reforçar as identidades locais, sem que, com isso, as identidades locais venham rejeitar a modernidade. 
em permanências nesse espaço, pois são construções que representa o modo de vida ribeirinho, cristalizado. São casas típicas de ambiente ribeirinho, reproduzidas também em áreas de terra firme, não apenas de madeira, mantendo o formato de palafita. É a forma-conteúdo de um modo de viver que compreende a presença da floresta e do rio, mas que, ainda assim, é urbano.

É uma paisagem que guarda em si os diferentes estágios que não apenas designaram a ação dos agentes produtores de regulação normativa e atividades econômicas, como o Estado e as empresas, mas que reflete o caráter local das relações sociais que produziram no espaço urbano o sentido característico de vida, entre natureza, relações sociais e pobreza (OLIVEIRA, 2017).

O ribeirurbano é um espaço que pode ser percorrido a pé em um tempo de no máximo uma hora, com uma noção de distância imediata, diferente das longas distâncias percorridas pelo rio para a entrada da própria cidade, ou, até mesmo, as longas distâncias percorridas entre o interior e a área urbana. É uma alternativa de proximidade, em contraponto às longas distâncias produzidas pelos rios.

O ribeirurbano é ethos. É o rio como imaginário social, simbologia, lenda. É a floresta, não apenas como recurso subsistente, mas como histórias e fábulas. São representações simbólicas, expressas nas hortas ou açaizais que existem nos quintais das casas como cultura adquirida de seus antepassados que viviam no interior como base alimentar.

Isso porque o urbano na Amazônia é heterogêneo: é uma mistura de estilos de vida rural e de vida na aglomeração, reforçada pela enorme diversidade de produtos extrativos que compõem o conjunto importante de bens que circulam no meio urbano. Para alguém de fora da região, isso evoca elementos tradicionais numa sociedade em processo de mudança (NUNES, 2008, p. 55)

É a permanência do movimento popular nas festividades religiosas, calendários de orientação católica, que dinamizam a vida social, bem como as igrejas evangélicas com seus congressos. É o ethos urbano presente na permanência do carimbó, na festa do boi, nas representações e crendices indígenas, no consumo do açaí, da farinha, da mandioca e do peixe, no transporte a barco, muitos, inclusive, encontrados nos quintais de casas que se comunicam diretamente com o rio. É o movimento da cidade em que seus comércios, a circulação de pessoas, as atividades dos funcionários públicos quase param, ou param no período aproximado das 12 às 15 horas devido ao intenso sol. 
São os moradores receptivos, alegres e sempre em busca de apresentar a cidade para o turista, como aqueles que oferecem café com leite em uma xícara em suas casas, com suas convidativas varandas. Às vezes, ressabiados com entrevistas e aplicação de formulários universitários, logo compartilham sua vida: a busca laboriosa para além da sobrevivência e a ênfase nos laços com a sua cidade.

A dinâmica desse espaço ribeirurbano ainda se denota no período noturno, quando sua pequenez é revelada pelo silêncio típico de uma vida urbana tímida, na qual as conexões sociais e econômicas dependem do dia, com a chegada das embarcações e da dinâmica interna intensa nas manhãs. À noite, restam alguns movimentos ligados aos cultos religiosos e algumas áreas de lazer e esporte, poucos estabelecimentos comerciais abertos, com exceção de lanchonetes e pequenos restaurantes em funcionamento nos períodos de férias e festas com maior movimento de pessoas.

Assim, o ribeirurbano é o lugar e também o habitante, que anima as formas, com seu modo de vida. Quando se tem a impressão de que os aspectos visíveis destas cidades são caóticos, o visível não revela o tempo da ação, seja como norma, seja como exercício, pois, como afirmou Santos, “a política dos pobres é baseada no cotidiano vivido por todos, pobres e não pobres, e é alimentada pela simples necessidade de continuar existindo" (SANTOS, 2006, p. 132).

O ribeirurbano espaço e homem é baseado em redes de solidariedade, na busca da complementação de renda, na renda não monetária, isto é, na troca de produtos e serviços entre os habitantes e na subsistência presentes em seus quintais. $\mathrm{O}$ circuito inferior da economia que se apoia no consumo, é presente nessa realidade. Formado por atividades de pequenas dimensões e voltado principalmente aos pobres, o circuito inferior é um subsistema do comércio em geral, ligado às atividades artesanais, transporte tradicional, prestação de serviços simples, sem trabalhos permanentes com número limitado de empregos (SANTOS, 2008, p. 22).

A rede urbana não é uma rede que comporta a circulação apenas do capital. A intenção é de suprir necessidades, de transporte de alimentos de primeira necessidade, de acesso a oportunidades como escola e hospital, de trocas de produtos, movimentos religiosos, que existe mesmo se não houvesse a atuação do Estado como agente interventor. Assim, este ribeirurbano é resistência diante de forças nacionais e internacionais externas à sua realidade. Apesar das provocações que estas forças possam causar dentro deste espaço amazônico, sua figura, como 
portador de um modo de vida em um ritmo próprio ao que lhe é imposto, concretiza um "espaço-tempo que homens e mulheres habitam e são habitados", na possibilidade de produção e controle de possibilidades "de espacialidades articulada à terra, às florestas e aos rios” (OLIVEIRA, 2016, p. 199 e 200).

O ribeirurbano reforça a tese de Santos de que a força dos pobres é seu tempo lento (SANTOS, 2013, p. 74), mas também é o lugar e o indivíduo, é a compreensão dos elementos compostos neste espaço geográfico das cidades ribeirinhas, a partir da percepção da paisagem: são espaços com pouca infraestrutura, com existência de casas e prédios de arquitetura colonial, casas de madeira ao lado de casas de alvenaria, quadras de esporte, unidades escolares de ensino fundamental e médio, e, unidades de polos universitários de ensino à distância que oferecem, em sua maioria, cursos de licenciaturas.

Com torres de celular e internet instalados há aproximadamente 10 anos, antenas parabólicas ou de operadoras de canal fechado, serviços de internet via rádio, cabos de eletricidade subaquáticos e modernos eletrodomésticos em meio às casas de madeira são aspectos da paisagem que guardam simplicidade e uso da modernidade em meio à floresta, até mesmo em comunidades do interior destes municípios.

São as relações com a modernidade tecnológica e de consumo de massa, na sociedade da informação e do conhecimento, da qual todos são parte, mas há ali (ou aqui), de outra maneira, uma indigenização da modernidade ${ }^{3}$ (SAHLINS, 1997), isto é, sobre o modo de vida de povos tradicionais aliado ao sistema capitalista mundial do mundo ocidental, em como se dá o contato com a modernidade e o reforço da própria identidade (Figura 3).

No caso do ribeirurbano, tem-se, inclusive, a coexistência com a permanência das cidades dos notáveis (SANTOS, 1993): as famílias tradicionais nas áreas rurais, donas de terras que têm alianças com famílias tradicionais nas áreas urbanas que se perpetuam na política, a presença dos religiosos na vida comunitária, espiritual e até mesmo política do povo, como os padres e os pastores, o tabelião, o professor, o radialista, o opositor político participante de grupos sociais, o juiz, o comerciante, entre outros personagens presentes de maneira simbólica ou presencial no cotidiano desse ambiente amazônico.

Não se pretende nesse artigo estabelecer julgamentos ou esgotar a compreensão sobre as cidades ribeirinhas da Amazônia, por isso, o ribeirurbano é mais que o espaço como o imaginamos urbanizado. É um modo de vida, entre

3 Justamente por participarem de um processo global de aculturação, os povos "locais" continuam a se distinguir entre si pelos modos específicos como o fazem (SAHLINS, 1997, p. 57). 
a paisagem rururbana e uma agitação social, que aos olhos externos é tímida, mas quando adentramos mais nesse local, percebemos as diferenças entre as comunidades ribeirinhas distantes no município e do que é o espaço urbano. $\mathrm{O}$ ribeirurbano é um modo de vida entre o aqui e o acolá: é o indivíduo em suas múltiplas identidades.

Figura 3 - A cultura, a religiosidade e a tecnologia na paisagem ribeirurbana
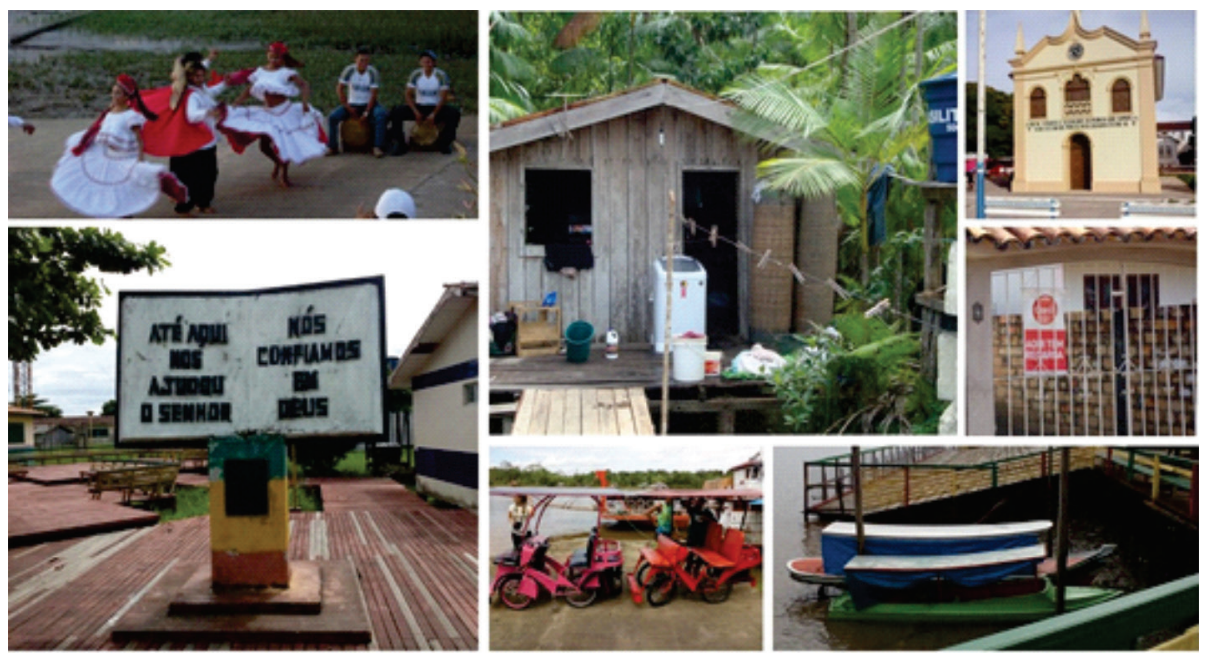

Da esquerda para a direita: dança do carimbó em Ponta de Pedras; Praça da Bíblia em Afuá; casa ribeirinha com máquina de lavar roupa no rio Fortaleza, Igreja Matriz, e casa com propaganda de operadora de celular em Ponta de Pedras; bicitáxi em Afuá.

Fonte: Laboratório de Estudos das Cidades - UNIVAP, 2015.

É um cidadão local, da terra, dos quintais florestados, dos sabores locais, da vida simplificada na busca das oportunidades do instante. É um cotidiano que evoca o retorno: quem sai para trabalhar, quem vai estudar fora leva seus hábitos e muitos voltam para sua terra. É parte da urbanodiversidade (TRINDADE JR., 2013, p. 20) que compreende a existência intraurbana que se articula com a floresta, que revela a pluralidade da região em suas formas espaciais e em seus conteúdos urbanos. Como afirmou Trindade Júnior (2013):

A urbanodiversidade assim entendida é revelada não somente por diversas formas de cidades e pela existência de múltiplos tipos de urbanização que decorrem normalmente de processos originados externamente à região, mas também por formas complexas de espaços que indicam a hibridização de relações definidas por contatos e resistências em face desses movimentos de diferentes naturezas que chegam à região (TRINDADE JR., 2013, p. 18). 


\section{CONSIDERAÇÕES FINAIS}

É necessário compreender as pequenas cidades amazônicas como espaços ribeirurbanos, dentro de um país com pluralidade, desde aspectos naturais aos socioespaciais. Geralmente, investimentos estatal ou empresarial são acompanhados de um discurso de modernização como se a realidade ribeirinha fosse "atrasada" no sentido ideológico da teoria da modernização (LEYS, 2004), pois está dentro de um discurso sudestino sobre o Brasil e "ecológico" sobre a Amazônia, como se o modo de viver urbano não existisse ali, uma vez que não segue padrão metropolitano brasileiro. Esperamos contribuir para a mudança dessa compreensão e o incentivo para a realização de políticas públicas sem a negação dessa realidade.

É compreender que existe um contexto de análise da sociedade concreta (SOUZA, 2013), necessária quando a preocupação é o desenvolvimento de uma determinada localidade, pois, o ribeirurbano, espaço e homem, é possuidor de características que expressam uma realidade singular, com elementos naturais e sociais essenciais para o direcionamento de políticas públicas que não levem em consideração apenas uma condição de espaço caótico, desestruturado, empobrecido e carente estruturalmente, quando sua realidade deveria ser mais investigada. É a busca de um novo modelo cívico, proposto por Santos (2014a), que o desenvolvimento de um lugar não deve levar apenas em consideração as questões econômicas, mas a cultura, a religiosidade, as instituições e a realidade local.

Por fim, as cidades ribeirinhas da Amazônia ainda permanecem com o eterno desafio da produção de sua existência, nesta dura vida, apesar de já emergirem grupos sociais e indivíduos dispostos a insistir em sua alteridade socioespacial, em um movimento de "dentro para fora" com vozes locais.

E neste sentido é que existe a esperança, nestas vozes que ecoam "de dentro". E com os autores que permitiram este artigo mergulhar nesta realidade dura, fascinante, poética, cheia de indignações e plena de ensino sobre outro urbano, façamos ecoar que existe, do outro lado do rio, talvez longe das vistas das grandes cidades, um saber viver capaz de nos fazer compreender que o ribeirurbano é do brasileiro e o brasileiro de todo lugar, em solidariedade, deve ser ribeirurbano. 


\section{REFERÊNCIAS}

BECKER, B. K. Fronteira e urbanização repensadas. Revista Brasileira de Geografia, Rio de Janeiro, v. 47, n. 3/4, p. 357-371, jul./dez. 1985.

BECKER, B. K. Amazônia: geopolítica na virada do III milênio. Rio de Janeiro: Garamond, 2009.

BECKER, B. K. A urbe amazônida: a floresta e a cidade. Rio de Janeiro: Garamond, 2013.

CARLOS, A. F. A. O lugar no/do mundo. São Paulo: Labur Edições, 2007. 85 p.

CARMO, M. B. S. A singularidade do urbano de Barcarena, como cidade ribeirinha da região amazônica. 2015. 106 f. Dissertação (Mestrado em Planejamento Urbano e Regional) - Instituo de Pesquisa e Desenvolvimento, Universidade do Vale do Paraíba, São José dos Campos, 2015.

CARVALHO, D. A. Na curva do rio: o manejo sustentável do pirarucu reestruturando a rede urbana no rio Solimões. In: SCHOR, T. (Org.). Dinâmica urbana da Amazônia brasileira. Manaus: Editora Valer, 2014. p. 109-133

CARVALHO, D. F; CARVALHO, A. C. Crescimento econômico na fronteira e a dinâmica urbana na Amazônia paraense: uma abordagem histórica. Novos Cadernos NAEA, Belém, v. 15, n. 1, ago. 2012.

CORRÊA, R. L. A periodização da rede urbana da Amazônia. Revista Brasileira de Geografia, Rio de Janeiro, v. 49, n. 3, p. 39-69, jul. 1987.

COSTA, S. M. F. et al. Entre a cidade legal e a cidade ilegal: a realidade das pequenas cidades da Amazônia - um estudo de Ponta de Pedras, Pará. URBE. Revista Brasileira de Gestão Urbana (Brazilian Journal of Urban Management), Curitiba, v. 6, n. 1, p. 127 139, jan./abr. 2014.

COSTA, S. M. F.; ROSA, N. C. O processo de urbanização na Amazônia e suas peculiaridades: uma análise do delta do rio Amazonas. Revista Políticas Públicas \& Cidades, [S. 1.], v. 5, n. 2, p. 81-105, out. 2017. ISSN: 2359-1552.

COSTA, S. M. F. et al. Cidades pequenas do estuário do rio Amazonas: terra de quem? Acta Geográfica, Boa Vista, v. 9, p. 19-35, 2015.

COSTA, S. M. F. et al. Crescimento urbano e ocupação de várzea em pequenas cidades da Amazônia: uma discussão premente. Geografia, Ensino \& Pesquisa, Santa Maria, v. 20, n. 1, p. 114-129, 2016.

CRUZ, V. C. O rio como espaço de referência identitária: reflexões sobre a identidade ribeirinha na Amazônia. In: TRINDADE JR., S.-C. C.; TAVARES, M. G. C. (Orgs.). Cidades ribeirinhas da Amazônia: mudanças e permanências. Belém: EDUFPA. 2008. p. 611-616. 
GODFREY, B. J.; BROWDER, J. O. Disarticulated urbanization in the Brazilian Amazon. Geographical Review, [S. 1.], v. 86, n. 1, p. 441-445, 1996.

GOMES, P. C. C. Quadros geográficos: uma forma de ver, uma forma de pensar. Rio de Janeiro: Bertrand Brasil, 2017.

HALL, S. A identidade cultural na pós-modernidade. 10. ed. Rio de Janeiro: DP\&A Editora, 2005.

INSTITUTO DE GEOGRAFIA E ESTATíSTICA (IBGE). Diretoria de Pesquisas, Coordenação de Populações e Indicadores Sociais. Pesquisa de Informações Básicas Municipais 2014. Disponível em: http://www2.ibge.gov.br/home/estatisticas/economia/ perfilmunic/2014/default.shtm. Acesso em: jan. 2018.

LEYS, C. Samuel Huntington: the end of classical modernization theory. In: LEYS, Colin. The rise $\&$ fall of development theory. Bloomington \& Indianápolis: Indiana University Press, 2004. p. 64-79.

LIMA, V. M. Globalização e saúde na Amazônia: um estudo de uma pequena cidade - Ponta de Pedras, Ilha de Marajó, Pará. 2017. 200 f. Tese (Doutorado em Ciências) Faculdade da Saúde Pública, Universidade do Estado de São Paulo, São Paulo, 2017.

MACHADO, L. O. Urbanização e mercado de trabalho na Amazônia brasileira. Cadernos IPPUR, Rio de Janeiro, v. 13, n. 1, p. 110-137, 1999.

MONTOIA, G. R. M. Planejamento participativo em pequenas cidades da Amazônia: um estudo de caso no município de Ponta de Pedras-PA. 2010. 142 f. Dissertação (Mestrado em Planejamento Urbano e Regional) - Universidade do Vale do Paraíba, São José dos Campos, 2010.

MONTOIA, G. R. M. As escalas decisórias das políticas públicas e dos programas de investimento e a repercussão no local: um estudo das pequenas cidades do delta do rio Amazonas. São José dos Campos: Universidade do Vale do Paraíba, 2018.

MORAES, A. C. R. Geografia: Pequena História Crítica. 20. ed. São Paulo: Annablume, 2005.

MOREIRA, E. Amazônia: o conceito e a paisagem. Rio de Janeiro: SPVEA, 1960. (Coleção Araújo Lima, 3).

MOREIRA, B. H. C. Ocupações irregulares em pequenas cidades da Amazônia: um estudo em Vila dos Cabanos, Barcarena, Pará, no período de 2005 a 2015. 2016. 103 f. Dissertação (Mestrado em Planejamento Urbano e Regional) - Universidade do Vale do Paraíba, São José dos Campos, 2016.

NUNES, B. F. A interface entre o urbano e o rural na Amazônia brasileira. In: CASTRO, E. M. R. (Org.). Cidades na floresta. São Paulo: Annablume, 2008. p. 41-58

OLIVEIRA, J. A. A cultura, as cidades e os rios na Amazônia. Ciência e Cultura, São Paulo, v. 58, n. 3, set. 2006. 
OLIVEIRA, J. A. A produção da cidade na Amazônia: Tempos e Espaços de Ações e Reações. In: SPOSITO, E. S. et al. (Org.). A diversidade da Geografia brasileira: escalas e dimensões da análise e da ação. Rio de Janeiro: Consequência Editora, 2016. p. 193-210. OLIVEIRA, I. G.; COSTA, S. M. F. Análise da percepção ambiental dos moradores de área de várzea urbana de uma pequena cidade do estuário do Rio Amazonas. Paisagem e Ambiente, São Paulo, n. 40, p. 151-167, dez. 2017.

OLIVEIRA, J. A.; SCHOR, T. Das cidades da natureza à natureza das cidades. In: TRINDADE JR., S-C.; TAVARES, M. G. C. (Orgs.). Cidades ribeirinhas da Amazônia: mudanças e permanências. Belém: EDUFPA, 2008. p. 15-26.

PRESSLER, N. Econegócios e cooperação internacional: novos discursos sobre a Amazônia. In: BOLLE, W.; CASTRO, E. M. R.; VEJMELKA, M. (Orgs.). Amazônia: região universal e teatro do mundo. São Paulo: Globo, 2010. p. 161-183.

RANGEL, J. A. O programa "Minha Casa, Minha Vida" e seus desdobramentos no local: um estudo da pequena cidade de Ponta de Pedras, Pará. 2011. 165 f. Dissertação (Mestrado em Planejamento Urbano e Regional) - Instituto de Pesquisa e Desenvolvimento, Universidade do Vale do Paraíba, São José dos Campos, 2011.

RATZEL, F. O solo, a sociedade e o Estado. Traduzido de "Le sol, la societé et al l'Etat', in La géographie politique por Mário Antonio Enfrásio. Revista do Departamento de Geografia, São Paulo, n. 18, p. 93-101, ago. 1982.

SAHLINS, M. O "pessimismo sentimental" e a experiência etnográfica: por que a cultura não é um "objeto" em via de extinção (parte I). Mana [online], v. 3, n. 1, p. 41-73, 1997.

SANTOS, M. A urbanização brasileira. São Paulo: Hucitec, 1993.

SANTOS, M. Por uma geografia nova. São Paulo: EDUSP, 2002.

SANTOS, M. Por uma outra globalização: do pensamento único à consciência universal. 13. ed. Rio de Janeiro: Record, 2006.

SANTOS, M. O espaço dividido: os dois circuitos da economia urbana nos países subdesenvolvidos. 5. ed. São Paulo: EDUSP, 2008.

SANTOS, M. Técnica, espaço, tempo: globalização e meio técnico-científicointernacional. 5. ed. São Paulo: EDUSP, 2013.

SANTOS, M. O espaço do cidadão. 7. ed. São Paulo: EDUSP, 2014a.

SANTOS, M. Espaço e método. 5. ed. São Paulo: EDUSP, 2014b.

SANTOS, M. A natureza do espaço: técnica e tempo, razão e emoção. 4. ed. 8. reimpr. São Paulo: EDUSP, 2014c.

SANTOS, G. R. et al. Hortas urbanas: a produção de hortaliças nos quintais da cidade de Lábrea, Amazonas, Brasil. In: SCHOR, T. (Org.). Dinâmica urbana da Amazônia brasileira. Manaus: Editora Valer, 2014. p. 135-150 
SATHLER, D. As redes para além dos rios: urbanização e desequilíbrios na Amazônia Brasileira. 2009. 178 f. Tese (Doutorado em Demografia) - Centro de Desenvolvimento e Planejamento Regional, Universidade Federal de Minas Gerais, Belo Horizonte, 2009.

SCHOR, T. (Org.). Dinâmica urbana da Amazônia brasileira. Manaus: Editora Valer, 2014.

SOUZA, M. L. Os conceitos fundamentais da pesquisa sócio-espacial. Rio de Janeiro: Bertrand Brasil, 2013.

TRINDADE JR., S-C. C. Laços \& nós: dinâmicas sub-regionais e interfaces cidade-rio na Amazônia. Revista Geográfica de América Central, Número Especial EGAL, 2011-Costa Rica, p. 1-16, II sem. 2011.

TRINDADE JR., S-C. C. Das "cidades na floresta" às "cidades da floresta": espaço, ambiente e urbanodiversidade na Amazônia brasileira. Papers do NAEA, Belém, n. 321, dez. 2013.

TRINDADE JR., S-C. C.; SILVA, M. A. P.; AMARAL, M. D. B. Das “janelas” às "portas” para os rios: compreendendo as cidades ribeirinhas da Amazônia. In: TRINDADE JR., S-C. C.; TAVARES, M. G. C. (Orgs.). Cidades ribeirinhas da Amazônia: mudanças e permanências. Belém: EDUFPA. 2008. p. 27-48.

VALOTA, E. C. S. Sociedade e natureza: análise da paisagem e da ocupação urbana em ambiente de várzea no bairro de uma pequena cidade do Estuário Amazônico: Ponta de Pedras-PA. 2015. 162 f. Dissertação (Mestrado em Planejamento Urbano e Regional) - Instituto de Pesquisa e Desenvolvimento, Universidade do Vale do Paraíba, São José dos Campos, 2015.

VICENTINI, Y. Cidade e história na Amazônia. 1994. Tese (Doutorado em Planejamento Urbano) - Faculdade de Arquitetura e Urbanismo, Universidade de São Paulo, São Paulo. 1994.

WAGLEY, Charles. Uma comunidade amazônica: estudo do homem nos trópicos. Tradução: Clotilde da Silva Costa. São Paulo: Companhia Editora Nacional, 1957. 